\title{
Using Facebook Ads as a Recruitment Strategy for Web Surveys on Drugs: Experience from the European Web Survey on Drugs
}

JERKOVIĆ. D. ${ }^{1}$, LOTAR RIHTARIĆ, M. ${ }^{2}$, VAN LAAR, M. ${ }^{3}$, HORVAT, T. ${ }^{4}$, UDRISARD, R. ${ }^{5}$, MATIAS, J. ${ }^{6}$

1 | University Psychiatric Hospital Vrapče, Croatia (Office for Combating Drug Abuse of the Government of the Republic of Croatia - at the time of conducting the survey)

2| Faculty of Education and Rehabilitation Sciences, University of Zagreb, Croatia

3| Trimbos Institute, the Netherlands

4 | Croatian Meteorological and Hydrological Service, Croatia (European

Monitoring Centre for Drugs and Drug Addiction, Portugal - at the time of conducting the survey)

$\mathbf{5}$ | School of Criminal Science, University of Lausanne, Switzerland

6 European Monitoring Centre for Drugs and Drug Addiction, Portugal
Citation | Jerković, D., Lotar Rihtarić, M., van Laar, M., Horvat, T., Udrisard, R., Matias, J. (2019). Using Facebook Ads as a Recruitment Strategy for Web Surveys on Drugs: Experience from the European Web Survey on Drugs. Adiktologie, 19(2), 67-74; https://doi.org/10.35198/01-2019-002-0002
BACKGROUND: General population surveys present a useful tool for getting information on drug use prevalence, but they often fail to reach a sufficient number of users, which is required to get detailed information on use patterns or other characteristics. Web surveys, especially when they use social networking sites, might present a complementary mechanism for getting a better picture of drug use by reaching hard-to-reach populations. AIM: The main objective of this study was to examine Facebook advertisements as a recruitment strategy in the "European Web Survey on Drugs: patterns of use", a project organized by the European Monitoring Centre for Drugs and Drug Addiction. METHODS:

Recruitment campaigns invited adults aged 18+ years who had consumed at least one drug (cannabis, MDMA/ ecstasy, amphetamines, or cocaine) in the past 12 months to complete an online survey. The advertisements were created in Facebook's Advertisement program and were used in Croatia, Switzerland, and the Netherlands. RESULTS: Among the eligible participants recruited via Facebook ( $N=5256), 68.1 \%$ were from Croatia, $24.4 \%$ from Switzerland, and $7.5 \%$ from the Netherlands. The Croatian and Swiss participants were younger and more likely to be males compared to the Dutch participants. Chi-square tests showed that there were significant differences in the frequency of drug use between the samples from the different countries for almost all drugs. CONCLUSION: The Facebook recruitment strategy was successful in reaching young adults, as well as recreational drug users, although the costs, campaign duration, available budget, and content of the ad images differed among the countries.

Keywords | Europe - Web survey - Drug Use - Facebook Advertisements - Recruitment

Grant affiliation | The preparation of this manuscript was supported by the European Monitoring Centre for Drugs and Drug Addiction (EMCDDA) (Contract code: CT.16.EPI.0123.1.0) with the aim of supplementing basic initial analysis within the European Web Survey on Drugs, conducted by the EMCDDA in cooperation with national partners. The Faculty of Education and Rehabilitation Sciences of the University of Zagreb financed the proofreading of the manuscript by an independent third party. 


\section{INTRODUCTION}

Recruiting participants for drug-related surveys is challenging because illicit drug use is a sensitive topic. General population surveys provide only limited insights into drug use since rates of illicit substance use are low. Methods exist to recruit "hidden populations", such as snowballing or respondent-driven sampling, but they can be quite time-consuming and costly.

A simpler and less expensive alternative may be online surveys, which, especially if conducted via social networking sites, can be effective ways to collect information on delicate issues (Brickman Bhutta, 2012; van Gelder et al., 2010; Ramo \& Prochaska, 2012), to reach young adults (Batterham, 2014; Chu \& Snider, 2013; Jones et al., 2012; Ramo et al., 2010), and to access hard-to-reach populations (Batterham, 2014; Barratt et al., 2015; Kayrouz et al., 2016). Social desirability seems to influence online survey responses less than responses in traditional surveys (Kreuter et al., 2008).

\subsection{Facebook as a recruitment tool}

According to Statista (2019a), Facebook is the most popular form of social media, with 2.2 billion active users per month. It is also the third most popular website in the world (Alexa, 2019). Because of the social nature of Facebook, this platform is very suitable for reaching potential survey participants, since a person can like a page, make comments, and share information (Gilligan et al., 2014; Pedersen \& Kurz, 2016). One of the recognized advantages of using Facebook for surveys is time-effectiveness. In line with that, Kayrouz et al. (2016) showed that Facebook strategies (e.g. boosting posts) recruited participants 2.5 times faster than the traditional strategies. Mychasiuk and Benzies (2011) found that Facebook was effective at improving participant retention in a longitudinal intervention study. Facebook advertisements were effective at recruiting individuals to health-related surveys (Thornton et al., 2016).

Facebook is increasingly popular for conducting online surveys for health research (Choi et al., 2017; Chu \& Snider, 2013; Kapp et al., 2013). However, there is limited literature on using Facebook for recruiting participants in drug-related surveys (Amon et al., 2014; Thornton et al., 2016).

\subsection{Facebook advertisements for recruiting to health-related surveys}

In a systematic review of Facebook use in health, medical, and psychosocial research, Thornton et al. (2016) identified three main advertising strategies: (1) broad inclusion criteria based on information on Facebook (age, gender, location, and language); (2) specific inclusion criteria not routinely collected by Facebook, in which case the advertisements feature wording and images that highlighted the focus of the survey, and (3) more specific inclusion criteria, in which case the advertisements appeared on the Face- book pages of users who listed interests or likes related to the survey topic. The recruitment costs were similar for the first and third strategies, which were significantly less expensive than the second strategy (Thornton et al., 2016). In order to overcome the self-selection bias that can occur with Facebook advertisements, Kapp et al. (2013) used basic targeting, which resulted in a broad reach, but a low response rate. Surveys that recruit through Facebook advertisements may be especially suitable for young adults (Choi et al., 2017; Chu \& Snider, 2012; Fenner et al., 2012; Ramo \& Prochaska, 2012; Whitaker et al., 2017), though the content of the advertisement can influence recruitment rates, engagement, and participant characteristics (Choi et al., 2017). For example, advertisements focusing on a problem perform better than those that are framed positively (Batterham, 2014; Choi et al., 2017), and simple advertisements seem to be more acceptable than complex ones with sophisticated messages (Ramo et al., 2014). While surveys that recruit through Facebook advertisements may lead to the overrepresentation of some groups (Whitaker et al., 2017), they are useful for targeting large numbers of drug users.

\subsection{The present study}

This paper used Facebook advertisements to recruit users in three European countries (Croatia, Switzerland, and the Netherlands) for an online survey on drug use. The work in this paper is part of the first wave of the "European Web Survey on Drugs: patterns of use" project coordinated by the European Monitoring Centre for Drugs and Drug Addiction (EMCDDA) in 2016, in which six countries (Croatia, the Czech Republic, France, the Netherlands, Switzerland, and the United Kingdom) participated using different strategies to recruit drug users to a survey on drug use. Each country devised its own sampling strategy: spreading information on social media, advertising on websites, recruiting through friends, info websites, print media, drug helplines, and advertising at drug services and in recreational settings. Among the strategies that were applied, Croatia, France, the Netherlands, and Switzerland used Facebook advertisements. Since France linked the national drug monitoring organization's website to Facebook advertisements, participants who were recruited by this method could not be identified. Therefore, the aim of this paper was to compare Facebook advertisement strategies and participant characteristics across Croatia, the Netherlands, and Switzerland in order to gain insights for optimising Facebook advertisements for drug-related surveys in Europe.

\section{METHODS}

\subsection{Participants}

The recruitment campaign invited individuals who lived in Croatia, Switzerland, or the Netherlands who were at least 18 years old and who had consumed at least one drug (cannabis, MDMA/ ecstasy, amphetamines, or cocaine) in the past 12 months to complete an online survey about their patterns of drug use. 


\subsection{Recruitment through Facebook advertising}

Facebook advertisements were created using the Facebook Ads program. Advertisements were displayed to Facebook users whose profiles indicated a location in Croatia, Switzerland, or the Netherlands, an age of at least 18, and a language - English (regardless of country), Croatian in Croatia, French or German in Switzerland, and Dutch in the Netherlands. Besides these criteria, the advertisements in Croatia were targeted on the basis of 28 additional criteria potentially connected to drug use, including the names of popular singers, DJs, music festivals, and popular clubs. The advertisements were run for different periods in 2016: two weeks (4-18 April) in Croatia, six weeks (22 May-4 July) in Switzerland, and three weeks (9-29 September) in the Netherlands.

The Facebook advertisements comprised a title ("European Web Survey") and the following main text: "Do you use drugs, even just once in the last 12 months? Tell us about it and respond to a survey which will affect the shaping of the European policy towards drugs. Anonymous and fast!" The advertisements also included a hyperlink to the survey website, and an image of a young girl lying on a sofa and seemingly floating in space (Croatia and Switzerland) or of young people dancing at a music event (Netherlands).

The Facebook advertisements were purchased through the cost-per-link click model (Facebook, 2019), as in previous work (e.g. in Ramo \& Prochaska, 2012; Fenner et al., 2012), because the focus was on people clicking through to the survey. The total cost of the advertisements was $€ 1232.00$ in Croatia, $€ 1672.39$ in Switzerland, ${ }^{1}$ and $€ 100.00$ in the Netherlands. These differences reflected the fact that Facebook advertisements were only one of the recruitment tools employed in each country, and the mix of tools (e.g. Facebook ads, Facebook organic reach, Google ads, leaflets, forums, advertising on info websites), as well as the budget that was allocated, differed across the countries.

All advertisements were shown in the News Feed area on the Desktop and Mobile interfaces. Some advertisements were also placed in the Right Column on the Desktop interface. In Croatia, one of the two advertisements was also displayed in the Right Column and in the Audience Network - All Placements section on the Mobile interface. In Switzerland, three advertisements were run, differing in language and placement. Only one advertisement was run in the Netherlands. One of the Croatian advertisements and two of the Swiss ones were defined as posts and therefore were sharable.

\subsection{Survey procedures}

This survey was conducted by the Office for Combating Drug Abuse of the Government of the Republic of Croatia and the

1 | The total amount was $1791 \mathrm{CHF}$; the currency rate from 31/12/2016 was applied (http://chf.fxexchangerate.com/eur-2016_12_31-exchange-rateshistory.html).
Faculty of Education and Rehabilitation Sciences of the University of Zagreb in Croatia, Addiction Suisse, the Ecole des Sciences Criminelles of the University in Lausanne in Switzerland, and the Trimbos Institute in the Netherlands.

Participants could come to the survey through two channels: by clicking on the hyperlink within the Facebook advertisement, or by arriving at a Facebook page used for this research, which individuals could like, post, or share. After clicking on the hyperlink in the Facebook advertisement, individuals were directed to the Lime Service survey website, where they were first informed that the aim of the survey was to gather information about how patterns of drug use vary in Europe. The participants were informed that the survey was anonymous and confidential, that IP addresses would not be collected, and that the aggregate results would only be used for research purposes. In the Netherlands, participants could voluntarily participate in a lottery, in which case they had to enter their email addresses, but this information was stored separately from the survey responses. Individuals were informed that in order to take part in the survey, they had to be at least 18 years old and had to have consumed cannabis, MDMA, amphetamines, or cocaine at least once in the last 12 months. They were asked to provide informed consent to participate in the study and were informed that they could discontinue the activity at any time without consequences. They were then asked a series of questions. Participation required 10 minutes on average.

During the recruitment campaign, the Facebook page for the survey in Croatia was monitored and comments/posts were deleted if they might have a negative effect on recruitment, such as inaccurate statements that the police were monitoring who participated in the survey.

The data was stored and cleaned by the EMCDDA. Survey responses were excluded if they showed obvious deficiencies or if the respondents indicated that they were younger than 18 or had not consumed the indicated drugs within the last 12 months. It was impossible to exclude repeat responses because IP addresses were not recorded; however, the data does not suggest that this substantially affected the results.

\subsection{Survey measures}

The survey, containing 128 questions, was a modified version of the questionnaire used by Trautmann et al. (2013). The questions covered general demographics, the characteristics of drug use, and drug availability. The participants were asked to answer a series of questions about the following types of drugs: (1) cannabis (hashish and/or marijuana), (2) MDMA/ecstasy, (3) amphetamines/methamphetamines, and (4) cocaine (powder). When participants decided to answer questions on multiple drugs, the drug modules were shown in random order. The IBM SPSS Statistics 21.0 software was used to obtain descriptive statistics (frequencies and Chi-Squares). 


\section{RESULTS}

\subsection{Cost-benefit analysis of Facebook recruitment to the online drug survey}

Table 1 shows the differences between the countries in terms of the number of advertisements and their total cost, reach, and recruitment performance. On the basis of an analysis of the participants with the Facebook Universal Resource Locator, the vast majority of the participants arrived at the survey directly from the advertisements, while small percentages arrived when the advertisement was shared in a post: $2.8 \%$ for both advertisements in Croatia, $2.8 \%$ for the German advertisement in Switzerland, and 9.5\% for the French advertisement in Switzerland.

The strategy in Croatia yielded an exceptionally high number of clicks and the lowest cost-per-click among the three countries. Conversely, the cost-per-click was highest in Switzerland. Among all the people who clicked on the advertisements in each country, $24.2 \%$ were eligible and decided to participate in Croatia, 29.8\% in Switzerland, and $55.7 \%$ in the Netherlands.

The Facebook strategy in the present study reached a diverse range of potential participants and generated relatively high proportions of eligible respondents. Interestingly, the recruitment strategy was more specific in Croatia than in the other two countries, and this generated the largest number of clicks, but the lowest proportion of completed surveys. The recruitment methods used in Croatia and the Netherlands were more cost-effective than the one used in Switzerland, even though the Swiss campaign lasted longest.

\subsection{Characteristics of participants in different countries}

The Croatian, Swiss, and Dutch participants differed in every demographic characteristic that was examined. Although men predominated over women in all three countries (Table 2), the proportion of male participants differed significantly. The proportion of older participants (especially 35-44 years old) was considerably higher in the Neth- erlands than in the other two countries. The proportions of participants who were employed part- or full-time were higher in Switzerland and the Netherlands, while the proportions of self-employed, unemployed, and student participants were higher in Croatia.

The proportions of women, older people, and employed were higher in the Netherlands than in the other two countries. Our data suggests that among drug users on Facebook, most of those in the Netherlands are 25-45 years old, whereas they are younger in Switzerland and Croatia.

\subsection{Differences in drug use between countries}

Cannabis had been consumed in the previous 12 months by $87.4 \%$ of the Croatian participants, $86.3 \%$ of the Swiss participants, and $65.8 \%$ of the Dutch participants. The proportions of participants using MDMA in the same timeframe were $37.1 \%$ in Croatia, 41\% in Switzerland, and $85.3 \%$ in the Netherlands, while the proportions of those who had used amphetamines were $30.8 \%$ of the Croatian, $29.6 \%$ of the Swiss, and $58.2 \%$ of the Dutch participants. Similarly, cocaine had been consumed by $25.2 \%$ of the Croatian participants, $33.8 \%$ of the Swiss participants, and $56.9 \%$ of the Dutch participants.

More detailed analysis of the frequencies of drug use shows differences across the three countries for all types of drugs (Table 3). The proportion of less frequent users of cannabis (resin or weed/skunk) was greater in the Netherlands than in the other two countries. The proportion of MDMA users who used this drug at least once per week was highest in Croatia, which also had the highest proportion of low-frequency cocaine users (less than once a month).

\section{DISCUSSION}

The Facebook advertisements strategy in Croatia resulted in a high number of clicks and the lowest cost-per-click among the three countries. The high number of clicks in Croatia can be explained by the higher interest in posting on Facebook because of a well-targeted campaign that resulted in a greater response. Further, the lowest cost-per-

\begin{tabular}{lccc}
\hline & Croatia & Switzerland & Netherlands \\
\hline Number of advertisements & 2 & 3 & 1 \\
\hline Total cost of advertisements & $€ 1,232.00$ & $€ 1,672.39$ & $€ 100.00$ \\
\hline Total reach & 598,401 & 231,921 & 23,656 \\
\hline Number of clicks & 14,791 & 4,292 & 707 \\
\hline Cost per click & $€ 0.08$ & $€ 0.39$ & $€ 0.14$ \\
\hline Number of participants & 3,581 & 1,281 & 394 \\
\hline Cost per participant & $€ 0.34$ & $€ 1.31$ & $€ 0.25$ \\
\hline
\end{tabular}

Table 1 | Performance of Facebook advertisements for recruiting to an on-line drug survey

Source: Jerković et al., 2017 


\begin{tabular}{|c|c|c|c|c|}
\hline & Croatia & Switzerland & Netherlands & pa \\
\hline & $n=3,581$ & $n=1,281$ & $n=394$ & \\
\hline \multicolumn{5}{|l|}{ Gender } \\
\hline Male & 62.2 & 67.7 & 54.3 & \multirow{3}{*}{$<.001$} \\
\hline Female & 36.6 & 31.9 & 45.4 & \\
\hline Transgender & 0.9 & 0.3 & 0.3 & \\
\hline \multicolumn{5}{|l|}{ Age group, yr } \\
\hline $18-24$ & 62.7 & 62.6 & 30.2 & \multirow{4}{*}{$<.00$} \\
\hline $25-34$ & 24.8 & 25.1 & 39.6 & \\
\hline $35-44$ & 5.9 & 8.2 & 23.4 & \\
\hline $45+$ & 1.8 & 3.3 & 5.8 & \\
\hline \multicolumn{5}{|l|}{ Employment status } \\
\hline Full-time & 33.1 & 41.2 & 53.4 & \multirow{6}{*}{$<.001$} \\
\hline Part-time & 5.3 & 12.5 & 18.1 & \\
\hline Self-employed & 7.7 & 5.9 & 6.6 & \\
\hline Student & 42.6 & 32.4 & 16.3 & \\
\hline Unemployed & 8.9 & 4.2 & 2.5 & \\
\hline Other & 2.4 & 3.9 & 3.7 & \\
\hline \multicolumn{5}{|l|}{ Type of living environment } \\
\hline City & 49.4 & 37.0 & 17.8 & \multirow{3}{*}{$<.001$} \\
\hline Town & 37.7 & 30.0 & 53.7 & \\
\hline Village & 12.9 & 32.9 & 28.5 & \\
\hline \multicolumn{5}{|l|}{ Household } \\
\hline Living alone & 31.6 & 48.0 & 32.2 & \multirow{4}{*}{$<.001$} \\
\hline Couple without children & 18.6 & 27.4 & 20.8 & \\
\hline Couple with child(ren) & 38.9 & 18.6 & 37.6 & \\
\hline One adult with child(ren) & 10.9 & 6.1 & 9.4 & \\
\hline
\end{tabular}

Table 2 | Demographic characteristics of eligible participants in the on-line drug survey

${ }^{a}$ Chi-squared test determined significant difference among the three countries

click may reflect the fact that advertising through Facebook is still in its early stages in Croatia, with relatively little market interest, so the costs are relatively low. On the other hand, the high cost-per-click in Switzerland might be because of strong competition for advertisement placement. The variation between the countries among the people who clicked on the advertisements and who were eligible and willing to participate may reflect differences in readiness to participate in a web survey and/or differences in interest in the topic.

Our results support and extend previous work demonstrating the importance and innovativeness of social networks for recruiting participants for health and psychosocial surveys (e.g. Amon et al., 2014; Kapp et al., 2013; Mychasiuk \& Benzies, 2012). They also show that effective recruitment depends more on specific targeting than on the duration of the campaign. In addition, recruitment outcomes may depend on how interesting or novel a survey appears (e.g. Facebook users in the Netherlands who are partygoers and clubbers are exposed to many surveys, whereas such surveys are infrequent in Croatia).
The differences in demographic characteristics among countries may reflect variations in the types of social networks through which the participants arrived at the recruitment advertisements on Facebook. They may also reflect differences in motivation to participate in online surveys. Consistently with our results, Van der Veer et al. (2018) showed that Facebook is quite popular among younger and older age groups in the Netherlands, while globally Facebook is most popular among people aged 18-34 years (Statista, 2019b). Further work is needed to understand what factors influence the different gender, age, and employment profiles of drug users in our three countries.

The proportions of last-year drug use in all three countries in this survey are much higher than the corresponding proportions from surveys of the general population. For instance, results from general population surveys showed that the last-year prevalence of cannabis use was $7.9 \%$ in Croatia, 7.3\% in Switzerland, and 8.7\% in the Netherlands (EMCDDA, 2017; Glavak Tkalić et al., 2016; Gmel et al., 2017). Similar results were observed for the other types of drugs covered by our survey when compared with the gen- 


\begin{tabular}{|c|c|c|c|c|}
\hline & Croatia & Switzerland & Netherlands & pa \\
\hline Cannabis resin use, $\% /$ total $n$ & $n=1,143$ & $n=615$ & $n=273$ & \\
\hline Daily & 12.4 & 14.3 & 4.8 & \multirow{5}{*}{$<.001$} \\
\hline Almost daily & 12.8 & 15.9 & 11.0 & \\
\hline Not daily but more than once a week & 16.0 & 13.0 & 13.2 & \\
\hline Once a week & 5.8 & 9.4 & 12.1 & \\
\hline Less than once a week, but at least once a month & 18.5 & 19.2 & 24.5 & \\
\hline Less than once a month & 34.5 & 28.1 & 34.4 & \\
\hline Cannabis weed/skunk use, $\%$ / total $n$ & $n=3,775$ & $n=1,157$ & $n=409$ & \\
\hline Daily & 15.9 & 20.1 & 15.9 & \multirow{6}{*}{$<.001$} \\
\hline Almost daily & 23.2 & 20.3 & 10.5 & \\
\hline Not daily but more than once a week & 22.3 & 15.0 & 17.8 & \\
\hline Once a week & 7.6 & 7.5 & 6.1 & \\
\hline Less than once a week, but at least once a month & 14.2 & 14.6 & 19.8 & \\
\hline Less than once a month & 16.9 & 22.5 & 29.8 & \\
\hline MDMA use, $\% /$ total $n$ & $n=1,454$ & $n=556$ & $n=546$ & \\
\hline Daily & 0.6 & 0.2 & 0.2 & \multirow{6}{*}{$<.001$} \\
\hline Almost daily & 1.0 & 0.2 & 0.5 & \\
\hline Not daily but more than once a week & 3.4 & 2.7 & 2.4 & \\
\hline Once a week & 7.6 & 5.0 & 2.9 & \\
\hline Less than once a week, but at least once a month & 22.3 & 21.8 & 28.9 & \\
\hline Less than once a month & 65.1 & 70.1 & 65.0 & \\
\hline (Meth)amphetamine use, \% / total $n$ & $n=1,074$ & $n=395$ & $n=341$ & \\
\hline Daily & 1.3 & 1.3 & 1.2 & \multirow{6}{*}{0.689} \\
\hline Almost daily & 3.4 & 3.5 & 3.2 & \\
\hline Not daily but more than once a week & 7.6 & 7.6 & 8.5 & \\
\hline Once a week & 9.8 & 10.1 & 5.6 & \\
\hline Less than once a week, but at least once a month & 23.8 & 21.5 & 24.3 & \\
\hline Less than once a month & 54.1 & 55.9 & 57.2 & \\
\hline Cocaine powder use, $\%$ / total $n$ & $n=911$ & $n=428$ & $n=321$ & \\
\hline Daily & 2.1 & 1.6 & 1.2 & \multirow{6}{*}{$<.001$} \\
\hline Almost daily & 2.1 & 3.5 & 0.6 & \\
\hline Not daily but more than once a week & 4.5 & 8.6 & 6.2 & \\
\hline Once a week & 4.4 & 6.3 & 5.3 & \\
\hline Less than once a week, but at least once a month & 15.6 & 21.7 & 27.7 & \\
\hline Less than once a month & 71.4 & 58.2 & 58.9 & \\
\hline
\end{tabular}

Table 3 | Frequency of drug use in the previous 12 months

a Chi-squared test determined significant difference across the countries

eral population surveys. The proportions of participants using MDMA in the previous 12 months among the general population in all three countries were below 3.4\%, amphetamine use was below 1.6\%, and cocaine use was below 1.9\% (EMCDDA, 2017; Glavak Tkalić et al., 2016; Gmel et al., 2017). The differences between the last-year prevalence of drug use in our survey and those conducted among the general population are expected, since the surveys of the general population were conducted using traditional methods on representative samples aged 15-64 in Croatia and the Netherlands, or on samples aged 15-75+ in Switzerland (EMCDDA, 2017; Glavak Tkalić et al., 2016; Gmel et al., 2017). Thus, the surveys involved a minority of drug users, whereas our survey selected drug users (Matias et al., 2019).
While samples from the general population are appropriate for prevalence studies, our focus was on drug users and their characteristics. While our results cannot provide estimates of the prevalence of drug use, it may be possible to estimate the amount of a drug consumed, as demonstrated by van Laar et al. (2013).

Taken together, our data suggests that using Facebook advertisements to recruit participants for an online drug survey can capture a relatively high percentage of "recreational" drug users, most of whom use a given drug less often than once a week. The only exception among the drugs covered in our survey was cannabis weed/skunk, for which the proportions of daily and almost-daily users were relatively 
high in our sample. While this data cannot provide reliable estimates of prevalence, it can provide insights into drug use and consumption patterns. Since traditional recruiting strategies tend to under-recruit recreational drug users (EMCDDA, 2019), Facebook advertisements may be used to complement the data that is gained.

\section{CONCLUSIONS}

Our results suggest that Facebook advertisements may be a time- and cost-effective strategy for recruiting the traditionally hard-to-reach group of young occasional drug consumers. This is consistent with prior research (Ramo \& Prochaska, 2012; Thornton et al., 2016). However, our con- clusions should be treated with caution in the light of several limitations. One is the fact that we used convenience sampling that was open to self-selection bias, which might influence the generalizability of our results. The second is the presence of many potential confounders, such as country-specific differences in Facebook's popularity among different age groups and types of drug users. The advertisements themselves differed in terms of their content and imagery, which may have affected the results. Our data cannot be used to estimate the prevalence of drug use. Since the participants from the three countries differed in all their demographic characteristics and in the frequency of use of the different types of drugs (cannabis, MDMA, cocaine), future work should investigate which targeting criteria might be useful for recruiting different types of drug users.
Acknowledgements: The authors wish to thank all the participants for taking the time to reply to the survey.

Authors' contributions: DJ and MLR designed the analysis presented here. DJ conducted the literature searches, and MLR conducted the statistical analysis. These two authors drafted the manuscript, which all the authors then improved and approved for publication.

The Faculty of Education and Rehabilitation Sciences of the University of Zagreb financed the proofreading of the manuscript by an independent third party.
Declaration of interest: DJ was selected by the European Monitoring Centre for Drugs and Drug Addiction to provide further analysis on the project "European Web Survey on Drugs: patterns of use - Croatia" (Contract code: CT.16.EPI.0123.1.0). JM is employed at the EMCDDA, while TH was a trainee at the EMCDDA in 2017. The study sponsor participated in the study design and collection of the data, but played no role in the analysis or data interpretation presented in this study, or in the decision about where to publish the study. None of the other authors declares any conflicts of interest.

\section{REFERENCES}

Amon, K. L., Campbell, A. J., Hawke, C., and Steinbeck, K. (2014). Facebook as a recruitment tool for adolescent health research: A systematic review. Academic Pediatrics. https://doi.org/10.1016/j.acap.2014.05.049

Alexa (2019). The top 500 sites on the web. (https://www.alexa.com/topsites) accessed 30 June 2019.

Barratt, M. J., Potter, G. R., Wouters, M., Wilkins, C., Werse, B., Perälä, J., et al. (2015). Lessons from conducting trans-national Internet-mediated participatory research with hidden populations of cannabis cultivators. International Journal of Drug Policy, 26(3), 238-249. https://doi.org/10.1016/j.drugpo.2014.12.004

Batterham, P. J. (2014). Recruitment of mental health survey participants using Internet advertising: content, characteristics and cost effectiveness. International Journal of Methods in Psychiatric Research, 23(2), 184-191. DOl:10.1002/mpr.1421

Brickman Bhutta, C. (2012). Not by the Book. Sociological Methods and Research, 41(1), 57-88. https://doi.org/10.1177/0049124112440795

Choi, I., Milne, D. N., Glozier, N., Peters, D., Harvey, S. B., and Calvo, R. A. (2017). Using different Facebook advertisements to recruit men for an online mental health study: Engagement and selection bias. Internet Interventions, 8 , 27-34. https://doi.org/10.1016/j.invent.2017.02.002

Chu, J. L., and Snider, C. E. (2013). Use of a social networking web site for recruiting Canadian youth for medical research. Journal of Adolescent Health, 52(6), 792-794. https://doi.org/10.1016/j.jadohealth.2012.12.002

European Monitoring Centre for Drugs and Drug Addiction (2017) The Netherlands, Country Drug Report 2017, Publications Office of the European Union, Luxembourg.

European Monitoring Centre for Drugs and Drug Addiction (2019). General population surveys key epidemiological indicator. Retrieved 9 July 2019, from http://www.emcdda.europa.eu/activities/gps

Facebook (2019). Facebook ads (https://www.facebook.com/business/products/ ads), accessed on 15 June 2019.
Fenner, Y., Garland, S. M., Moore, E. E., Jayasinghe, Y., Fletcher, A., Tabrizi, S. N., et al (2012). Web-Based Recruiting for Health Research Using a Social Networking Site: An Exploratory Study. Journal of Medical Internet Research, 14(1):e20., DOl: 10.2196/JMIR.1978

Gilligan, C., Kypri, K., and Bourke, J. (2014). Social networking versus Facebook advertising to recruit survey respondents: A quasi-experimental study. Journal of Medical Internet Research, 16(9). https://doi.org/10.2196/resprot.3317

Glavak Tkalić, R., Miletić, G-M., and Maričić, J. (2016). Uporaba sredstava ovisnosti u hrvatskom društvu: Istraživanje na općoj populaciji. Zagreb: Institut društvenih znanosti Ivo Pilar i Ured za suzbijanje zlouporabe droga Vlade Republike Hrvatske.

Gmel, G., Kuendig, H., Notari, L., and Gmel, C. (2017). Suchtmonitoring Schweiz Konsum von Alkohol, Tabak und illegaler Drogen in der Schweiz im Jahr 2016. Sucht Schweiz.

Jerković, D., Lotar Rihtarić, M., and Horvat, T. (2017), Facebook ads as recruitment for online drug surveys: the Holy Grail? Lisbon Addictions conference presentation (http://www.emcdda.europa.eu/system/files/ attachments/6843/11H00_2_Dijana\%20Jerkovic.ppt) accessed on 20 June 2019

Jones, L., Saksvig, B. I., Grieser, M., and Young, D. R. (2012). Recruiting adolescent girls into a follow-up study: Benefits of using a social networking website. Contemporary Clinical Trials, 33(2), 268-272. https://doi.org/10.1016/j.cct.2011.10.011

Kapp, J. M., Peters, C., and Oliver, D. P. (2013). Research recruitment using Facebook advertising: Big potential, big challenges. Journal of Cancer Education, 28(1), 134-137. https://doi.org/10.1007/s13187-012-0443-z

Kayrouz, R., Dear, B. F., Karin, E., and Titov, N. (2016). Facebook as an effective recruitment strategy for mental health research of hard to reach populations. Internet Interventions, 4(May 2014), 1-10. https://doi.org/10.1016/j.invent.2016.01.001 
Kreuter, F., Presser, S., and Tourangeau, R. (2008). Social desirability bias in CATI, IVR, and web surveys: The effects of mode and question sensitivity. Public Opinion Quarterly, 72(5), 847-865. https://doi.org/10.1093/poq/nfn063

Matias, J., Kalamari, E., Mathis, F., Skarupova, K., Noor, A., Singleton, N., and European Web Survey on Drugs Group (2019). The use of multi-national web surveys for comparative analysis: Lessons from the European Web Survey on Drugs. International Journal of Drug Policy, Available online 9 April 2019, https://doi.org/10.1016/j.drugpo.2019.03.014

Mychasiuk, R., and Benzies, K. (2012). Facebook: An effective tool for participant retention in longitudinal research. Child: Care, Health and Development, 38(5), 753-756. https://doi.org/10.1111/j.1365-2214.2011.01326.x

Pedersen, E. R., and Kurz, J. (2016). Using Facebook for health-related research study recruitment and program delivery. Current Opinion in Psychology, 9, 38-43. https://doi.org/10.1016/j.copsyc.2015.09.011

Ramo, D. E., and Prochaska, J. J. (2012). Broad Reach and Targeted Recruitment Using Facebook for an Online Survey of Young Adult Substance Use. Journal of Medical Internet Research, 14(1):e28) doi: 10.2196/jmir.1878

Ramo, D. E., Hall, S. M., and Prochaska, J. J. (2010). Reaching young adult smokers through the Internet: Comparison of three recruitment mechanisms. Nicotine and Tobacco Research, 12(7), 768-775. https://doi.org/10.1093/ntr/ntq086

Thornton, L., Batterham, P. J., Fassnacht, D. B., Kay-Lambkin, F., Calear, A. L., and Hunt, S. (2016). Recruiting for health, medical or psychosocial research using Facebook: Systematic review. Internet Interventions, 4, 72-81. https://doi.org/10.1016/j.invent.2016.02.001

Trautmann, F., Kilmer, B., and Turnbull, P. (Eds.) (2013). Further Insights into aspects of the illicit EU drugs markets. European Commission - Directorate General for Justice. Luxembourg: Publication Office of the European Union.

Statista (2019a), Most famous social network sites worldwide as of April 2019, ranked by number of active users (https://www.statista.com/statistics/272014/ global-social-networks-ranked-by-number-of-users/), accessed on 13 June 2019.

Statista (2019b), Facebook: distribution of global audiences as of April 2019, by age and gender (https://www.statista.com/statistics/376128/facebook-globaluser-age-distribution/), accessed on 13 June 2019.

Van der Veer, N., Boekee, S., Hoekstra, P., and Peters, O. (2018). Nationaal Social Media Onderzoek 2018. Het grootste trendonderzoek van Nederland naar het gebruik en verwachtingen van social media \#NSMO. Newcom Research and Consultancy B.V. Retrieved 15 June 2019 from https://www.bindinc.nl/wpcontent/uploads/2018/04/Newcom-Nationale-Social-Media-Onderzoek-2018-3.pdf

Van Gelder, M. M., Bretveld, R. W., and Roeleveld, N. (2010). Web-based questionnaires: The future in epidemiology? American Journal of Epidemiology, 172(11), 1292-1298. https://doi.org/10.1093/aje/kwq291

Van Laar, M., Frijns, T., Trautmann, F., Lombi, L. (2013). Sizing the Cannabis Market: A Demand-Side and User-Specific Approach in Seven European Countries. Current Drug Abuse Reviews, 6(2), 152-164. DOI: 10.2174/1874473706666131205152835

Whitaker, C., Stevelink, S., and Fear, N. (2017). The Use of Facebook in Recruiting Participants for Health Research Purposes: A Systematic Review. Journal of Medical Internet Research, 19(8);e290. doi: 10.2196/jmir.7071 